\title{
An Intergenerational Approach in the Promotion of Balance and Strength for Fall Prevention - A Mini-Review
}

\author{
Urs Granacher $^{\mathrm{a}}$ Thomas Muehlbauer ${ }^{\mathrm{a}} \quad$ Albert Gollhofer ${ }^{\mathrm{c}}$ Reto W. Kressig ${ }^{\mathrm{b}}$ \\ Lukas Zahner $^{\text {a }}$ \\ ${ }^{a}$ Institute of Exercise and Health Sciences, University of Basel, and b Division of Acute Geriatrics, Basel University \\ Hospital, Basel, Switzerland; ' Institute of Sport and Sport Science, University of Freiburg, Freiburg, Germany
}

\begin{abstract}
Key Words
Intergenerational training $\cdot$ Isometric/dynamic force production - Static/dynamic postural control
\end{abstract}

\begin{abstract}
The risk of sustaining a fall is particularly high in children and seniors. Deficits in postural control and muscle strength either due to maturation, secular declines or biologic aging are two important intrinsic risk factors for falls. During life span, performance in variables of static postural control follows a U-shaped curve with children and seniors showing larger postural sway than healthy adults. Measures of dynamic postural control (i.e. gait speed) as well as isometric (i.e. maximal strength) and dynamic muscle strength (i.e. muscular power) follow an inverted U-shaped curve during life span, again with children and seniors showing deficits compared to adults. There is evidence that particularly balance and resistance training are effective in counteracting these neuromuscular constraints in both children and seniors. Further, these training regimens are able to reduce the rate of sustaining injuries and falls in these age groups. An intergenerational intervention approach is suggested to enhance the effectiveness of these training programs by improving compliance and increasing motivation of children and seniors exercising together. Thus, the objectives of this mini-review are: (1) to describe the epidemiology and etiology of falls in children and seniors; (2) to discuss training programs that
\end{abstract}

counteract intrinsic fall risk factors by reducing the rate of falling, and (3) to present an intergenerational approach that has the potential to make training programs even more effective by including children and seniors together in one exercise group.

Copyright $\odot 2010$ S. Karger AG, Basel

\section{Introduction}

During the last 60 years, major demographic changes have been noticed in the world and particularly in Europe that primarily affected the youngest and oldest age groups. In 1950, 26.2\% of Europe's population were 14 years and younger, $11.0 \%$ were between 60 and 79 years, and only $1.1 \%$ were $\geq 80$ years. In $2005,15.9 \%$ were 14 years and younger, $17.1 \%$ were between 60 and 79 years, and $3.5 \%$ were $\geq 80$ years. Thus, the proportion of young people has decreased and that of elderly people has increased during the last 60 years, with the age group $\geq 80$ years being the fastest growing population in Europe's society [1]. Population projections indicate that the phenomenon of population aging will even be reinforced during the upcoming decades. In fact, in 2050, $15.0 \%$ of Europe's population will be 14 years and younger, $24.6 \%$ between 60 and 79 years, and $9.6 \%$ will be $\geq 80$ years [1]. One serious concern of industrialized countries is that demographic changes would undermine the sustainabil- 
Fig. 1. Development of the fall incidence rate across the life span $[3,10]$ and potential fall risk factors in children $[7,8]$ and seniors [9].

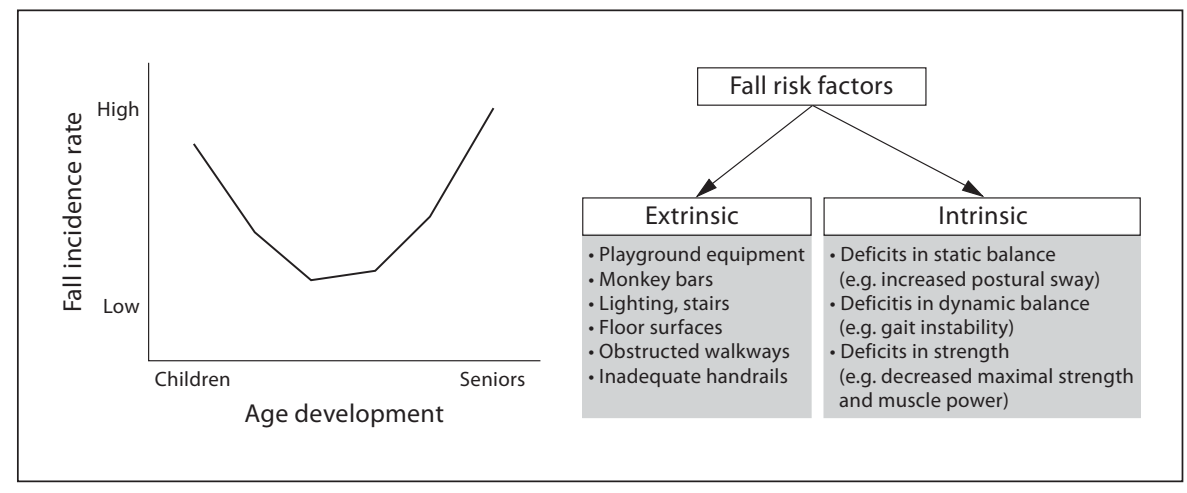

ity of the public health care system since per capita health expenditures are five times higher for people $>75$ years of age than for those aged 25-34 years. A major reason for high medical treatment costs in children and particularly in older adults is an increased prevalence of sustaining falls and fall-related injuries [2]. Therefore, the objective of this paper is threefold: (1) to review the literature concerning epidemiology and etiology of falls in children and seniors; (2) to describe the effects of adequate training regimens on fall risk factors in these age groups, and (3) to present a new intergenerational approach for the implementation of the training regimens.

\section{Risk of Falling}

Epidemiologic data have indicated that the risk of sustaining a fall is particularly high in children [3] and seniors [4]. According to international data, unintentional falls are a leading cause of morbidity and mortality in children [3]. Considering all incidences of pediatric trauma, falls are the most common reason for an emergency department visit. In fact, $25-34 \%$ of all pediatric trauma hospital admissions can be ascribed to falls. Injury rates due to falls are particularly high in infants $(0-5$ years) and young children (6-12 years) compared to adolescents (13-19 years). The reported injuries due to falls include soft tissue bruises, sprains, bone fractures and contusions [3]. These injuries may affect the children's attitude towards physical activity in the future in terms of an increased restriction of physical activity [5]. Further, annual medical treatment costs of fall-related injuries amount to approximately USD 933 million for the 0- to 19-year age group [6]. As in children, medical treatment costs are particularly high in seniors due to an increased prevalence of sustaining falls and fall-related injuries [2].
Twenty-eight to $35 \%$ of individuals over the age of 65 years sustain at least one fall over a 1-year period [4]. The occurrence rate increases to $32-42 \%$ in adults over the age of 75 years, and to $56 \%$ in adults aged $90-99$ years [4]. About $20 \%$ of falls need medical attention, and $15 \%$ of those result in severe injuries like joint dislocations, soft tissue bruises and contusions. The remaining 5\% cause fractures, with femoral neck fractures occurring at a rate of $1-2 \%$ in community-dwelling older adults. Fall-related injuries affect elderly individuals in terms of a poor quality of life caused by restricted mobility and functional decline. In the United States, the estimated direct medical costs for fatal and non-fatal fall-related injuries in the aging population totaled USD 19.2 billion in the year 2000 [2].

Given the high susceptibility of sustaining a fall during the early and late years of life, it is hypothesized that the rate of falling follows a U-shaped curve during life span with children and seniors showing the highest incidence rates (fig. 1).

\section{Etiology of Falls}

The etiology of falls is generally considered to be multifactorial, involving extrinsic (environmental) and intrinsic (patient-related) circumstances. Numerous epidemiological studies have identified a multitude of extrinsic and intrinsic risk factors for falling in children $[7,8]$ and seniors [9]. Extrinsic factors include playground equipment, monkey bars, lighting, stairs, furniture, floor surfaces, obstructed walkways and inadequate handrails, for example [7]. In terms of intrinsic fall risk factors, impaired static (e.g. increased postural sway) and dynamic postural control (e.g. gait instability) as well as deficits in muscle strength (e.g. impaired muscle power and rate of 
Fig. 2. Development of static and dynamic balance across the life span (schematic illustration based on data from two studies $[11,12])$ and training-induced changes in balance performance (flow chart based on data from various studies $[35,46,62,63])$ and fall/injury reduction in children [45] and seniors $[48,49]$. Note: a range is presented when more than two studies were cited.

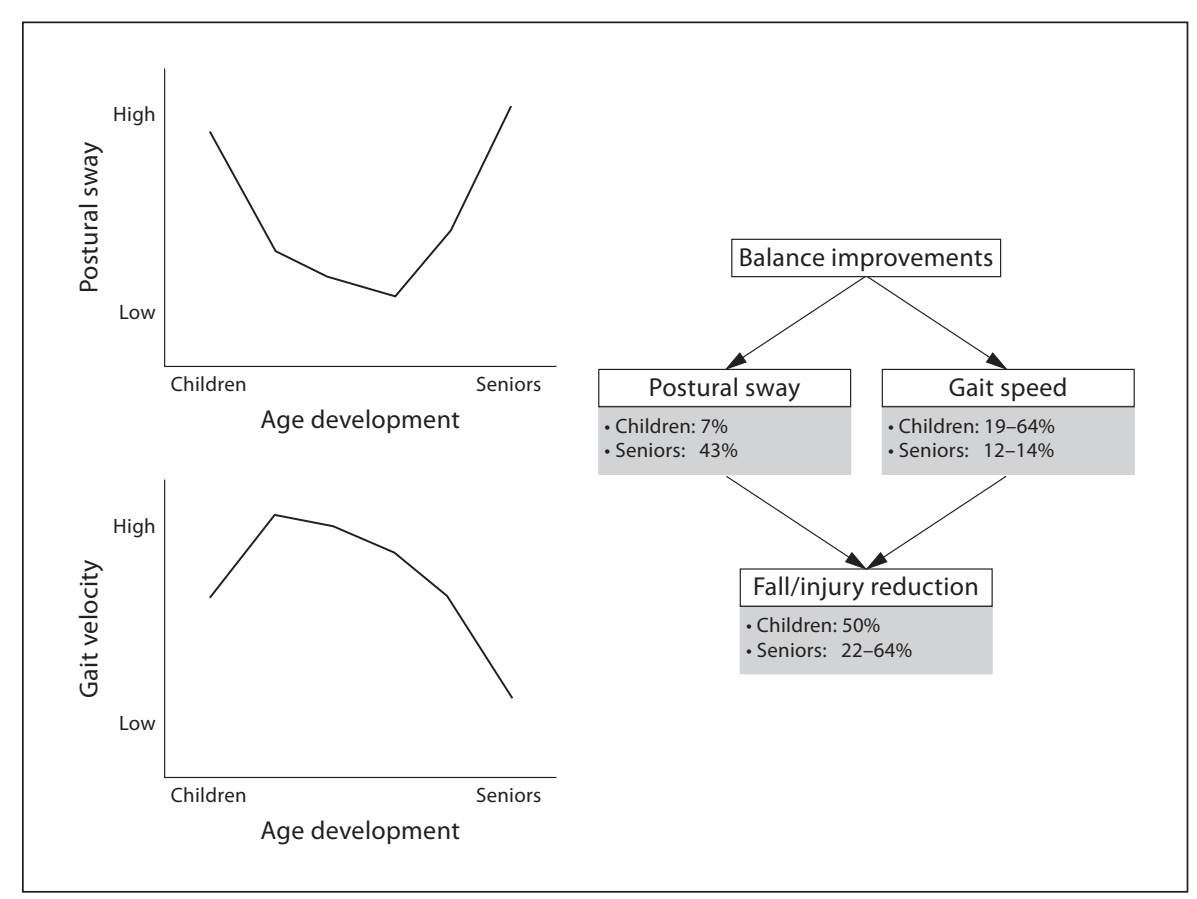

force development) have most frequently been reported to increase the risk of falling in these age groups [8].

\section{Deficits in Postural Control}

Postural control can be divided into a static and dynamic component and has been defined as the control of the body's position in space for the purpose of balance and orientation. Under static conditions, the base of support and the ground remain stationary and only the center of mass moves, whereas under dynamic conditions, both, the base of support and the center of mass shift. Dynamic balance control is more challenging because the center of mass remains at distinct phases of the gait cycle (single limb support) outside the base of support. Thus, it is not surprising that a large number of falls occurs during ambulation [10]. A person's individual risk for falls ultimately depends on the frequency of imbalance episodes encountered in everyday activities and the ability to recover from these balance-threatening situations. The ability to control posture can be described as a dynamic process across the life span. There is evidence that young children and older adults show the largest magnitudes of postural sway and the slowest gait speeds $[11,12]$. Therefore, a U-shaped dependency between measures of static balance and age [11] and an inverted Ushaped dependency between variables of dynamic balance and age [12] can be postulated (fig. 2).
Maturational deficits in static and dynamic postural control have been observed in children up to the age of 8 years compared to young healthy adults in terms of an increased postural sway, a slower gait speed, greater stride-to-stride variability during walking, as well as an impaired ability to compensate for platform perturbations $[11,12]$. Additionally, secular trends in balance performance over the past 25-35 years were reported recently [13].

What are the reasons for an impaired postural control in children? Foudriat et al. [14] investigated age-related sensory contributions to balance control in healthy children between the ages of 3 and 6 years using computerized dynamic posturography. They observed that the control of posture changes from being primarily visualvestibular to being somatosensory-vestibular between these ages, but that the transition to adult responses for all sensory conditions is not complete by the age of 6 years [14]. In another study, it was reported that children younger than 7.5 years are less able to suppress inappropriate visual and somatosensory inputs when tested on a moving platform [15]. Further, in a neurophysiologic approach, EMG responses to muscle stretch in the upper limb study were investigated in children. The results of this study indicated that long-latency EMG responses, probably involving supraspinal pathways, are already present at 2-3 years of age, but that the duration of these 
long-latency EMG responses did only show adult-like values after the age of 6-8 years [16]. Based on these results, it can be postulated that hierarchically lower level and primarily spinal motor centers mature before higher-level supraspinal motor centers. Both mechanisms, however, are necessary for the targeted coordination of balance control. These maturational deficits in postural control could be responsible for the high susceptibility of sustaining a fall in children. Further, Matton et al. [13] observed in a cross-sectional study that girls' performance in the Flamingo Balance Test (one-legged stance on a beam) was significantly impaired in 2005 compared to 1979-1980. Thus, maturational deficits and secular declines in the ability to control posture may account for the impaired balance performance in children and thus the increased risk of sustaining falls.

Whereas childrens' balance ability is most likely restricted by maturational deficits and secular declines, that of older adults suffers from biologic aging. In fact, it seems that age-related deteriorations in postural control start relatively early in life. Thus, Era et al. [17] already detected differences in static balance performance between young (30- to 39-year olds) and middle-aged adults (40- to 49year olds). Notably, these differences became even more pronounced after the age of 60 years. In terms of age-related effects on dynamic postural control, slower gait speeds, shorter stride length, a wider base of support, a greater proportion of the gait cycle in double-leg support, enhanced stride-to-stride variability during walking and inefficient balance strategies during the compensation of stance and gait perturbations were observed in older compared to young adults. In addition, Hausdorff et al. [18] found that stride-to-stride variability of stride time, stance time and swing time measured during a 6-min walk was significantly increased in elderly fallers compared to both elderly non-fallers and young subjects, indicating that measures of gait unsteadiness are suitable for fall risk assessment.

What are the underlying mechanisms for an impaired postural control in older adults? It was demonstrated in a series of studies that age-related deteriorations in static and dynamic postural control can mainly be attributed to cognitive impairment (e.g. gradual onset of cerebral white matter disease), visual (e.g. impairment in contrast sensitivity), vestibular (e.g. decline in vestibular neurons) and proprioceptive (e.g. polyneuropathies) dysfunctions, as well as muscle weakness (e.g. decline in the number and size of fibers, particularly type II muscle fibers). Taken together, these degenerative processes seem to be responsible for impaired postural control in old age and consequently for an increased risk of falling.

Fall Prevention in Children and Seniors
There is evidence in the literature that the control of posture is further limited in children and seniors when two tasks are concurrently conducted with the primary task involving a postural control task (e.g. standing or walking), and the secondary task a motor interference task (e.g. carrying a tray with a filled cup) or a cognitive interference task (e.g. backward counting) [19]. Blanchard et al. [20] examined postural control in quiet stance in children aged 8-9 years who performed either a counting backward or a reading task. Postural sway increased with simultaneous performance of either cognitive task. Granacher et al. [19] investigated the effects of a cognitive (i.e. serial subtractions by three) and/or a motor interference task (i.e. holding two interlocked sticks steady in front of the body) on static (i.e. bipedal stance on balance platform) and dynamic postural control (i.e. walking on an instrumented walkway) in young and elderly subjects. Irrespective of task condition, i.e. single task or multitask, elderly participants showed larger postural sway and greater strideto-stride variability than younger participants. Further, postural sway increased in the elderly and stride-to-stride variability in both groups with progression in task complexity [19]. In addition, Lundin-Olsson et al. [21] observed that elderly subjects who stopped walking when talking had a significantly increased risk of sustaining a fall within the next 6 months. Additionally, a recent systematic review on dual-task performance and the prediction of falls indicated that changes in performance whilst dual-tasking were significantly associated with an increased risk for falling amongst older adults [22].

What are the underlying reasons for an impaired postural control in children and seniors under multitask conditions? In general, a number of theories (e.g. capacity theory, bottle neck theory, cross-talk theory and neural structure theory) have been proposed to explain dualtask interference effects. All theories are based on the assumption that the brain has limited information-processing capacity, which is why a decrement in performance of one or both tasks can be observed. More specifically, children and seniors' sensory contributions to balance control are impaired compared to healthy young or middle-aged adults either due to maturational deficits or biologic aging. Given the diminished visual, proprioceptive and vestibular sensitivity, more of the child and elderly's attention is required to maintain postural stability, particularly in less stable situations. In other words, children and seniors try to compensate for their sensory dysfunctions by retrieving more attentional resources for dual-task processing. However, since the brain's capacity is limited, dual-task interference occurs. 
Fig. 3. Development of static and dynamic muscle strength across the life span (schematic illustration based on data from Larsson et al. [27]) and training-induced changes in strength performance (flow chart based on data from two studies [53, 64]) and fall/injury reduction in children [45] and seniors [65]. Note: a range is presented when more than two studies were cited.

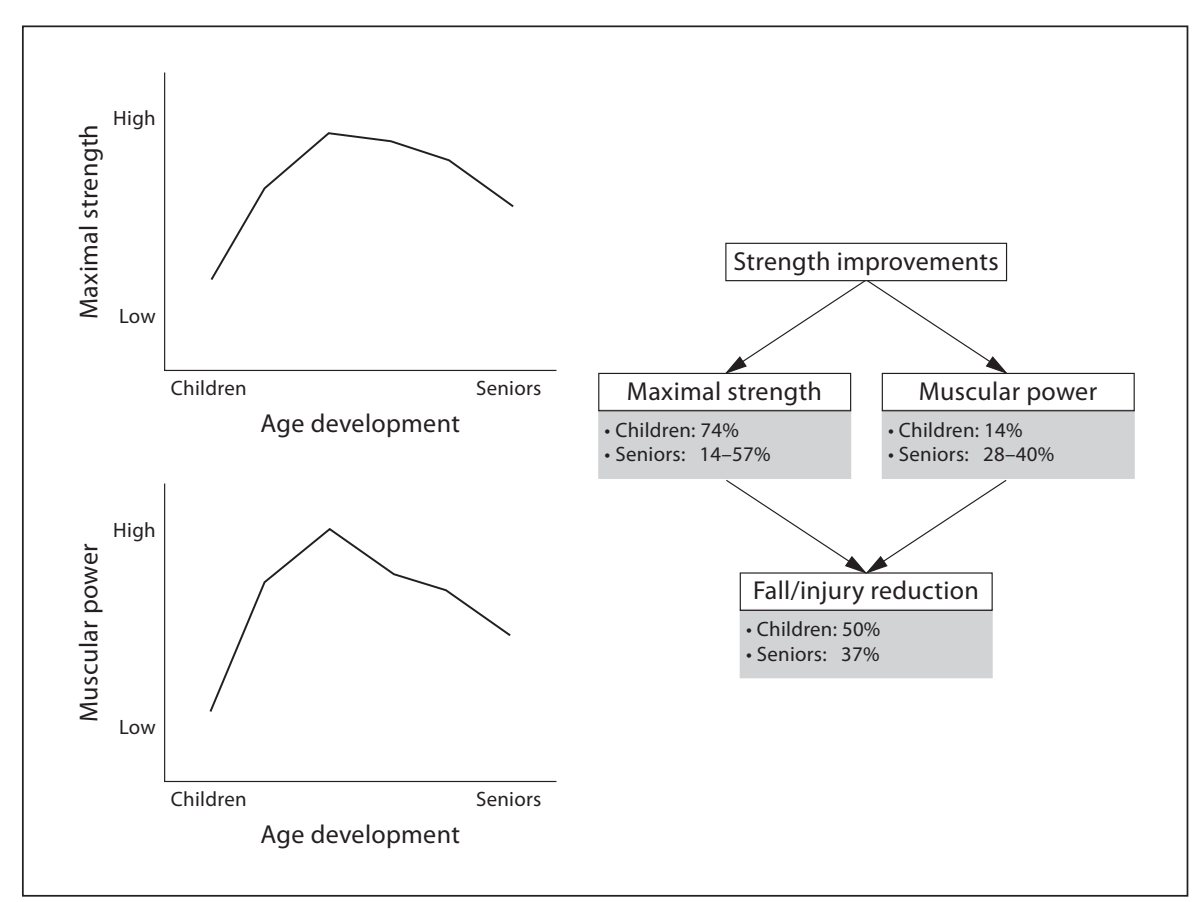

\section{Deficits in Muscle Strength}

In addition to postural control, muscle strength is another essential component of motor performance. Two established measures of strength, i.e. maximal strength and muscular power, are important prerequisites for activities of daily living and thus functional mobility. Maximal strength is often tested under isometric (static) conditions and is defined as the maximal force generated by a muscle or muscle group during a single maximal voluntary effort. Muscle power can be defined as the force applied multiplied by the velocity of movement, thus representing a dynamic component of muscle strength. Measures of isometric and dynamic muscle strength develop in an inverted U-shaped curve across the life span (fig. 3). Maximal strength and power increase linearly in boys until 13-14 years of age [23, 24]. Yet, as for postural control, secular declines in strength have been noticed in a cross-sectional study which investigated strength performance of different muscle groups in children in 1956 and 1981 [25]. The author reported relative decreases in strength over time that ranged from $6 \%$ for the back muscles to $14 \%$ for the leg extensors [25]. Thus, due to maturational deficits and secular declines, strength performance is remarkably lower in children compared to adults. In fact, Ferretti et al. [26] reported that leg extensor power during a jumping exercise was $65 \%$ lower in children aged 8-13 years compared to sedentary healthy adults aged 20-35 years. With the onset of puberty and the associated rise in circulating growth hormone level, acceleration in strength development can be noticed [23]. In girls, strength improves linearly with age through about 16-17 years with no clear evidence for an adolescent spurt as in boys [23]. Most studies of strength performance with age have shown maximum strength and power values between 25 and 30 years of age [24, 27]. Only slight decreases in strength and power can be noticed between the $3 \mathrm{rd}$ and 5 th decade of life [26, 27]. However, the rate of decline accelerates after the age of 50 years with the most severe losses occurring between the 7th and 9th decade of life [28]. More specifically, losses of $1-2 \%$ per annum in maximal strength and approximately $3.5 \%$ per annum in muscular power of the leg extensors were reported in adults aged $\geq 65$ years. Further, McNeil et al. [28] found a $25 \%$ decrease in dorsiflexor power between the $3 \mathrm{rd}$ and 7 th decade of life. This reduction was doubled in the next 2 decades, so that men in their 9th decade of life produced $60 \%$ less power than young men. From a functional or therapeutic point of view, it is of interest to know whether the performance level in maximal force and/or explosive power is associated with functional mobility and fall risk in old age. In fact, Bean et al. [29] observed that leg power is an important factor influencing the physical performance of mobility-limited older people. Although related to strength, it is a separate attribute 
that may exert a greater effect on physical performance. Further, Pijnappels et al. [30] identified lower-limb strength and rate of moment generation as limiting factors for balance recovery after tripping. They reported that maximum isometric push-off force in a leg press was the best measure to differentiate elderly fallers from nonfallers.

What are the underlying reasons for impaired muscle strength and power in children and seniors? Ferretti et al. [26] found a $45 \%$ smaller total cross-sectional area of the thigh and calf muscles in children (8-13 years) compared to adults (20-35 years). Given that muscle mass is directly related to the ability to generate force, reduced muscle mass seems to be a major factor for the described deficits in strength performance in children. In addition, neural factors could also play a role because Belanger and McComas [31] were able to show that complete simultaneous voluntary activation of plantar flexor motor units cannot be achieved at prepubertal age. Further, the prepubertal hormonal situation possibly affects the maximal rate of ATP hydrolysis and thus the generation of explosive force [26]. The decline in maximal strength and muscle power in old age is primarily caused by a reduced excitability of efferent corticospinal pathways resulting in lower levels of central muscle activation, a gradual loss of spinal motoneurons (particularly large $\alpha$-motoneurons) due to apoptosis, a subsequent decline in muscle fiber number and size (sarcopenia), especially of type II fibers, changes in muscle architecture and decreases in tendon stiffness.

\section{Fall Prevention in Children and Seniors}

Fall-preventive intervention programs can focus on intrinsic and/or extrinsic factors. From an exercise-scientific or therapeutic point of view, particularly intrinsic factors are of interest since those can be modified by adequate training programs [32-37]. However, guidelines for the prevention of falls in children are limited to extrinsic factors only [38]. According to those reports, fallpreventive strategies should include awareness campaigns like parents' education about the mechanisms of falls, recommendations on parental supervision during playing activities and the inspection of potential home environmental hazards (e.g. windows and balconies). However, published information on how to preventively counteract potential intrinsic fall risk factors is only sparse in children. Notably, it was postulated in a recent review that fall-preventive training programs should be incorporated in physical education curricula [39].
Guidelines for the prevention of falls in seniors encompass approaches which focus on extrinsic and/or intrinsic fall risk factors [40]. A systematic review and meta-analysis provides evidence that particularly multifactorial programs are effective in reducing both the risk and the rate of falling [41].

\section{Balance and Resistance Training}

The health benefits of balance (BT) and/or resistance training (RT) can primarily be described as a countermeasure to any circumstance where postural control and/or muscle weakness compromise function (e.g. activities of daily living, compensation of stance and/or gait perturbations). Thus, these training regimens make substantial contributions to thwart functional limitations and/or potential intrinsic fall risk factors in different age (e.g. children or seniors) or patient groups (e.g. patients with Parkinson's disease).

\section{Importance of Balance Training}

The effects of BT on postural control have been well established in the elderly. However, only little research has been conducted regarding the impact of $\mathrm{BT}$ on variables of balance control in children. Hadders-Agra et al. [42] scrutinized the impact of a 2-month BT program on postural responses during sitting on a moveable platform in healthy infants aged 5-10 months. They reported that training facilitated the most complete direction-specific postural response pattern and that it accelerated the development of response modulation. In a recent study, the effects of BT and detraining on measures of postural control and strength were investigated in healthy prepubertal children (age $7 \pm 1$ years) [35]. Four weeks of BT resulted in tendencies in terms of small-to-medium interaction effects yet not statistically significant improvements in postural sway, force production of the plantar flexors and vertical jumping height. Immaturity of the postural control system and/or deficits in attentional focus during practice of balance exercises could account for the observed findings [35]. Ledebt et al. [43] examined the effects of BT on stance and gait parameters in children aged 5-11 years with hemiplegic cerebral palsy. Following 6 weeks of training, limits of stability increased during stance, and symmetry of stance was improved. The results of the gait analysis indicated that the walking pattern became more symmetrical after the training. Recently, the effects of a school-based physical activity-related injury prevention program on risk behavior, neuromotor fitness and injury 
incidence was studied in children aged 10-12 years [44, 45]. The intervention lasted 1 school year and consisted of informative newsletters and posters for the children and their parents. In addition, 5-min exercises were given at the beginning and end of each physical education class aimed at improving muscle strength, speed, flexibility and coordination. The intervention program was not able to significantly improve injury-preventing behavior. Further training resulted in small non-significant improvements in neuromotor fitness in favor of the intervention group [44]. In addition, a substantial and relevant reduction in physical activity injuries (50\%), especially in children of the low-activity group, was found [45] (fig. 2). The results of these studies indicate that $\mathrm{BT}$ with children is effective in counteracting intrinsic fall risk factors and in reducing the rate of sustaining an injury.

During the last years, many studies were conducted on the impact of BT on postural control, muscle strength and fall incidence rate in older adults. Granacher et al. [37] examined the effects of a 13-week BT in men aged 60-80 years on their performance in clinical balance tests (functional reach test and tandem walk test) and on the ability to compensate for mediolateral perturbation impulses while standing on a two-dimensional balance platform. After training, performance in the clinical balance tests was significantly improved and summed oscillations of the balance platform were significantly reduced concomitant with an improved activation of muscles compensating for the perturbation impulse. In a more functional approach, Granacher et al. [32] investigated the impact of a 13-week BT in elderly men on the ability to compensate for decelerating gait perturbations while walking on a treadmill. Training resulted in a decrease in onset latency and an enhanced reflex activity in the prime mover compensating for the decelerating perturbation impulse. In another study, Granacher et al. [34] were able to show that 13 weeks of BT improved maximal strength and explosive force production of the leg extensors in a cohort of healthy, elderly males aged $60-80$ years. Silsupadol et al. [46] investigated the effects of single-task BT versus dual-task BT with fixed-priority instructions and dual-task BT with variable-priority instructions on gait speed under single (only walking) and dual-task conditions (walking while concurrently performing an arithmetic task) in elderly adults (mean age 75 years). Singletask BT involved the performance of balance exercises only (e.g. standing with eyes closed or tandem standing). The participants receiving dual-task BT with fixed-priority instructions practiced balance tasks while simultaneously performing cognitive tasks (e.g. naming objects), and were instructed to maintain attention on both postural and cognitive tasks at all times. Participants in the dual-task BT with variable-priority instructions performed the same exercises as the fixed instruction dualtask BT group, but spent half the session focused on balance and half focused on cognitive task performance. Following 4 weeks of BT, participants in all training groups significantly improved performance on singletask gait speed. However, only participants who received dual-task training (fixed and variable-priority instruction) were superior to the single-task training group in improving walking under dual-task conditions. These findings suggest that older adults are able to improve their walking performance under dual-task conditions only when specific types of training, i.e. dual-task training are performed.

BT seems to be a well-suited fall-preventive program for the elderly population since many intrinsic fall risk factors (e.g. muscle weakness or postural instability) are exercised and thus counteracted. A large number of epidemiologic studies and meta-analyses investigated the impact of BT on fall injury rate in seniors $[47,48]$. For example, Madureira et al. [48] observed a significant reduction in fall incidence rate following a 1-year BT program in women aged $\geq 65$ years. Sihvonen et al. [49] investigated the effects of a 4-week BT program on fall incidence in frail older women (age $81 \pm 6$ years). During the 12-month follow-up time, 55\% of the subjects in the experimental group and $71 \%$ in the control group had fallen. The authors reported a significantly enhanced proportion of recurrent falls and injurious falls in the control group compared to the BT group (fig. 2). Steadman et al. [50] conducted a 6-week progressive BT program with older adults (age $83 \pm 6$ years) and found a significant reduction in fall incidence rate in the intervention compared to the control group over a 24 -week period. An exemplified BT program that proved to be effective in children [35] and seniors [32-34, 37] is demonstrated in table 1 .

\section{Importance of Resistance Training}

The attitude towards the application of RT in different age and patient groups has changed throughout the last couple of years due to intensified research efforts. Today, RT has proved to be a safe and effective regimen to increase variables of strength performance in healthy children and seniors. A number of studies were able to prove $[51,52]$ that age-appropriate RT in children produces significant strength gains. Depending on the training status of the subjects, the applied training load, frequency and 
Table 1. Examples of effective exercise conditions used during BT in both children [35] and seniors [32-34, 37]

BT protocol

Exercises

- One-/two-legged stance, step stance, tandem stance

- On stable and unstable surfaces (e.g. soft mat, ankle disk, balance board, air cushion)

- With and without visual control

- With and without cognitive (e.g. counting backwards, naming animals) and motor interference tasks (e.g. catching and throwing a ball, holding a tray with a glass of water on it)

Training volume

- 8- to 12-week training period; each session lasts 45-60 min (5- to 10-min warm-up, 30-45 $\operatorname{min~BT,~5-10~min~}$ cooldown)

- Exercises consist of initially 4 sets which are performed for $20 \mathrm{~s}$ with a 40 -second rest between each set and with a 3 -min rest between each exercise in order to minimize fatigue

Training frequency

- 2-3 training sessions a week separated by approximately $24 \mathrm{~h}$

Training intensity

- Reduction in the base of support

- Reduction in the sensory input

- Inclusion of unstable surfaces

- Inclusion of cognitive/motor interference tasks

Similarities in the training protocols of children and seniors were extracted and brought together.

duration, the trained muscle groups and the applied testing methodology, strength gains range from 13 to $40 \%$ $[51,52]$. One study even documented a $74 \%$ increase in 10-repetition maximum (RM) strength of lower-extremity muscles following 8 weeks of training with 2 training sessions per week in children aged 8 years [53]. Given that Faigenbaum et al. [54] found increases in jumping performance, sprint and agility run time in boys aged 12-15 years after 6 weeks of combined plyometric and RT, it is suggested that training adaptations in children are specific to the movement pattern, velocity of movement, contraction type and contraction force applied during RT. To date, the question of whether RT is effective in reducing fall and/or injury rate in children is unresolved. However, there is preliminary evidence for adolescents suggesting that a preseason RT program can reduce sport-related injuries [55]. Given the compelling evidence regarding the impact of RT on strength performance in children and the limited transferability of these effects on motor skills, it seems appropriate to combine RT with other training regimens (e.g. BT) to induce effects on the rate of sustaining injuries and falls.

Aside from children, particularly seniors would substantially benefit from improvements in strength and motor performance in terms of enhanced functional mobility and improved quality of life. In this regard, Granacher et al. [36] investigated the effects of progressive RT on variables of strength performance and postural control in elderly men with an age range of 60-80 years. Thirteen weeks of training resulted in significant improvements in maximal strength and explosive force of the leg extensors with increases in explosive force exceeding those in maximal strength. In addition, an improved static and dynamic postural control was observed in clinical (functional reach test or tandem walk test) but not in biomechanical (mediolateral perturbation impulse) tests. In addition, a meta-analysis on the impact of progressive RT in older adults on measures of leg extensor strength and variables of standing balance revealed effect sizes of 0.68 and 0.11 , respectively [56]. Given that the ability to generate force rapidly is - from a fall-preventive point of view - more relevant than the capacity to produce maximal strength, it is of paramount importance to apply strength training programs which have the potential to enhance explosive force production. Recently, it has been suggested that high-velocity or power training has a greater impact on explosive force production capacity in the elderly than heavy-resistance strength training. Fielding et al. [57] were among the first to investigate the impact of a 16-week high-velocity versus low-velocity RT on variables of muscle strength and power of the knee and leg extensors in elderly women with self-reported disability. Both training groups exercised three times per week at an intensity of $70 \%$ of the 1-RM. After training, both groups improved their leg extensor 1-RM strength (high velocity: $35 \%$ and low velocity: $33 \%$ ) and knee extensor 1-RM strength (high velocity: $45 \%$ and low velocity: $41 \%$ ) to a similar extent. However, participants in the high-velocity strength training group experienced significantly greater improvements in leg press peak muscle power than those in the low-velocity training group (high velocity: $97 \%$ and low velocity: $45 \%$ ). Thus, it seems that the principle of training specificity directly applies to the training-induced adaptive processes following RT in older adults with large gains in variables of strength but only little improvements in measures of balance control. As a consequence, it is suggested to combine RT with BT to counteract intrinsic fall risk factors in seniors. This com- 
binatory approach is further reinforced when investigating the effects of isolated RT on the fall rate in seniors. To the authors' knowledge, there is no study available which was able to detect a fall-preventive effect of RT. Most studies used some combination of resistance, balance, endurance and flexibility exercises and found a reduced incidence of falling [58]. Further, a recent meta-analysis provides evidence that particularly the combination of balance- and strength-promoting exercises has an impact on intrinsic fall risk factors such as muscle weakness and deficits in postural control. This neuromuscular training regimen reduced the fall rate by $15-50 \%$ in older people aged 65-97 years living in the community [47]. An exemplified RT program that proved to be effective in children $[51,52]$ and seniors $[36,57]$ is demonstrated in table 2 .

\section{Intergenerational Approach for the Promotion of Balance and Strength}

King [59] postulated in her review article that increased attention should be paid to potential opportunities for children and grandchildren to influence the physical activity levels of older adults. She suggested increased interaction among scientists working at different points of the life span continuum to take advantage of a potential intergenerational synergy [59]. With reference to King [59] as well as on the basis of the described similarities in net balance and strength performance in children and seniors, an intergenerational approach for the promotion of balance and strength could have great potential. Typically, BT and strength training programs are offered in an age-specific manner, i.e. physical education for children and supervised group exercise for seniors. An alternative method of targeting children and seniors for health-enhancing fitness programs is to design intergenerational training regimes (e.g. granddaughters and grandmothers exercising together). This approach could help promoting the adoption and maintenance (high adherence rate) of a health-enhancing fitness program throughout the training period. Motivated by their mutual social support, participants can exercise and set goals together in order to enhance their fitness level.

Ransdell et al. [60], for example, investigated the effectiveness of a 12-week home or community-based physical activity intervention (including RT) that targeted daughters (15 \pm 1 years) and mothers ( $45 \pm 7$ years) to improve health-related fitness. Irrespective of the training group, daughters and mothers significantly enhanced their sit-up performance. In addition, push-up perfor-
Table 2. Examples of effective exercise conditions used during RT in both children $[51,52]$ and seniors $[36,57]$

\begin{tabular}{l} 
RT protocol \\
\hline Exercises \\
$\quad-$ Leg press \\
$\quad-$ Leg extension/flexion \\
$\quad-$ Calf raise \\
$\quad$ - Weight machine for hip abduction/adduction
\end{tabular}

Training volume

- 8- to 12-week training period; each session lasts 45-60 min (5- to 10-min warm-up, 30-45 min BT, 5-10 min cooldown)

- Exercises include three sets of 10-15 repetitions

- 2- to 3-min rest between sets

Training frequency

- 2-3 training sessions a week separated by approximately $48 \mathrm{~h}$

Training intensity

- $65-75 \%$ of the 1-RM; the 1-RM is defined as the maximum load that can be lifted in a single repetition for a given exercise

- Submaximal strength assessment tests can be used to detect the training load corresponding to $65-75 \%$ of the

1-RM; it was reported that a load that can be lifted 10 times corresponds to $75 \%$ of the $1-\mathrm{RM}, 12$ repetitions of a given load correspond to $67 \%$ of the $1-\mathrm{RM}$, and 15 repetitions to $65 \%$ of the $1-\mathrm{RM}[66]$.

- In terms of progression during training, the number of repetitions should be increased (e.g. from 10 to 15) before the training load is increased

Mode of contraction

- Participants should be instructed to perform the exercises with moderate contraction velocities

Similarities in the training protocols of children and seniors were extracted and brought together.

mance was significantly improved for mothers in the home and the community-based group. Despite the fact that both interventions resulted in positive effects, they were limited to adults but did not incorporate seniors. To overcome this limitation, Ransdell et al. [61] conducted another study with three generations exercising together. Over the duration of 6 months, daughters (aged 8-13 years), mothers (aged 30-50 years) and grandmothers (aged 50-70 years) performed a progressive physical activity program (including short series of 3-5 rotating RT activities) in a home-based context. As a result, muscular strength measured by push-ups improved significantly in the intervention compared to the control group over 


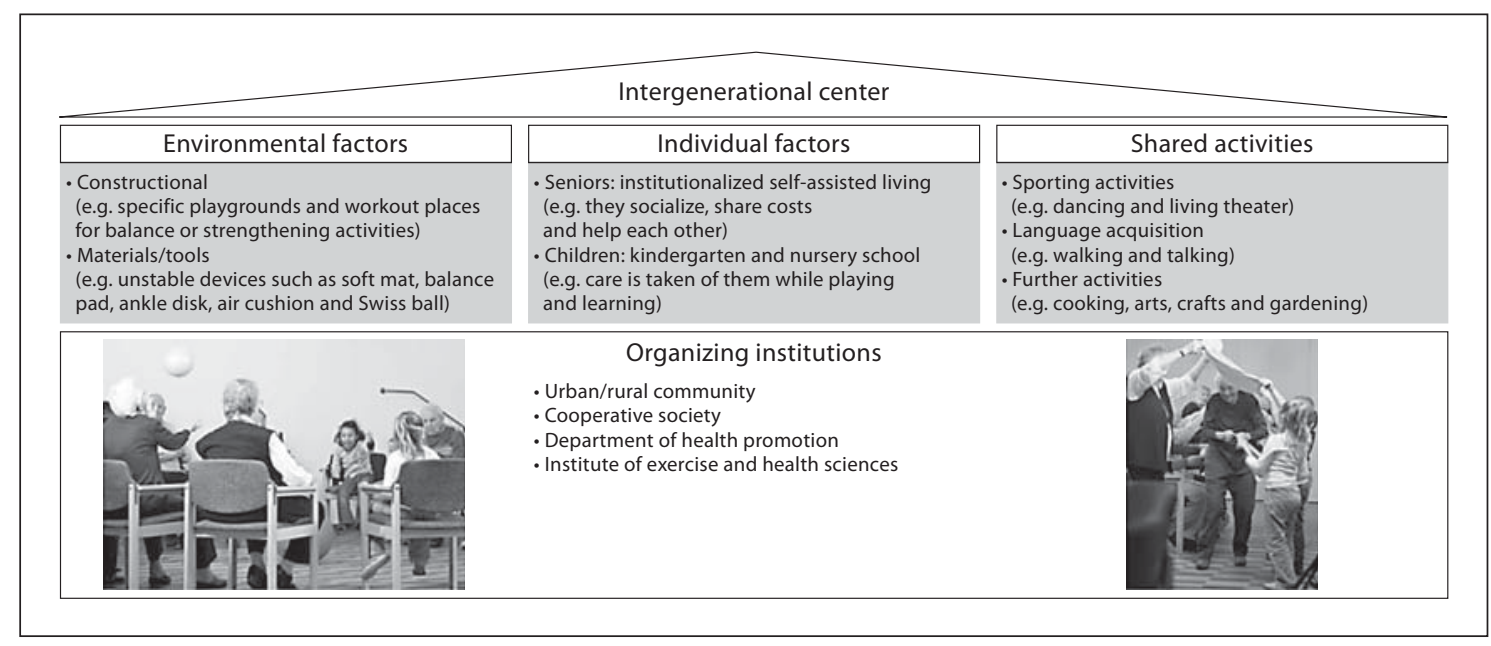

Fig. 4. Concept of the intergenerational center with children and seniors sharing their activities.

training. Due to the limited impact of training on strength performance only, future studies should incorporate BT and RT in their approach to find out whether intergenerational training is equal or even more effective in enhancing measures of balance and strength than agegroup-specific BT and/or RT training.

In a recent pilot study, we investigated the feasibility of an intergenerational center, which aimed at the promotion of a healthy lifestyle for children and seniors (fig. 4). The intergenerational center is based on the idea that children and seniors participate in ongoing services and/or programming concurrently at the same site, and interact during regularly scheduled planned intergenerational activities, as well as through informal encounters. The intergenerational center is composed of two program components, one that serves seniors (i.e. housing facility) and another that serves children (i.e. nursery school and kindergarten). Additionally, diverse facilities make use of shared activities that concurrently accommodate both generations (e.g. exercising, cooking, language acquisition and singing). Furthermore, environmental factors are considered in such a way that shared spaces/places were constructed which provide opportunities for spontaneous but also specific intergenerational interaction (e.g. balance and strengthening activities). The rural community as well as a cooperative society supported the project. It is expected that children and seniors thrive when resources are used to bring the generations together rather than separate them. Specific benefits expected from that concept are that physical activity, motor fitness and thus quality of life will be improved in all participants.

\section{Conclusion}

Deficits in postural control and muscle strength either due to maturation or biologic aging represent major intrinsic fall risk factors in children and seniors. In fact, the net output in these characteristics of neuromuscular performance is similar in children and seniors in terms of a U-shaped curve during life span in static balance control (i.e. postural sway) and an inverted U-shaped curve in dynamic balance control (i.e. gait speed), maximal strength (i.e. maximal strength under isometric conditions) and muscular power (i.e. applied force multiplied by the velocity of movement). Intervention studies indicated that particularly BT and RT are effective in counteracting these intrinsic fall risk factors in children and seniors. An intergenerational intervention approach is suggested to make these training programs even more effective by including children and seniors together in one exercise group with the goal to improve compliance and to enhance motivation of the participants. However, at this point there is only preliminary evidence available regarding the effectiveness of the intergenerational approach. Therefore, future studies should elucidate whether intergenerational intervention programs are equal or even more effective in the promotion of balance and strength than age-specific programs. 


\section{References}

1 United Nations: World Population Prospects: The 2008 Revision. New York, United Nations, 2009.

-2 Stevens JA, Corso PS, Finkelstein EA, Miller TR: The costs of fatal and non-fatal falls among older adults. Inj Prev 2006;12:290295.

- 3 Kahl H, Dortschy R, Ellsasser G: Injuries among children and adolescents (1-17 years) and implementation of safety measures. Results of the nationwide German Health Interview and Examination Survey for Children and Adolescents (KiGGS). Bundesgesundheitsblatt-GesundheitsforschungGesundheitsschutz 2007;50:718-727.

-4 Blake AJ, Morgan K, Bendall MJ, Dallosso H, Ebrahim SB, Arie TH, Fentem PH, Bassey EJ: Falls by elderly people at home: prevalence and associated factors. Age Ageing 1988;17: 365-372.

5 Kelm J, Ahlhelm F, Pape D, Pitsch W, Engel C: School sports accidents: analysis of causes, modes, and frequencies. J Pediatr Orthop 2001;21:165-168.

6 Mathers LJ, Weiss HB: Incidence and characteristics of fall-related emergency department visits. Acad Emerg Med 1998;5:10641070.

7 Crawley-Coha T: Childhood injury: a status report. J Pediatr Nurs 2001;16:371-374.

-8 Kambas A, Antoniou P, Xanthi G, Heikenfeld R, Taxildaris K, Godolias G: Accident prevention through development of coordination in kindergarten children (in German). Dtsch Z Sportmed 2004;55:44-47.

9 Lord SR, Sherrington C, Menz HB: Falls in Older People: Risk Factors and Strategies for Prevention, ed 2. Cambridge, Cambridge University Press, 2007.

10 Talbot LA, Musiol RJ, Witham EK, Metter EJ: Falls in young, middle-aged and older community dwelling adults: perceived cause, environmental factors and injury. BMC Public Health 2005;5:86.

11 Hytonen M, Pyykko I, Aalto H, Starck J: Postural control and age. Acta Otolaryngol 1993;113:119-122.

12 Oberg T, Karsznia A, Oberg K: Basic gait parameters: reference data for normal subjects, 10-79 years of age. J Rehabil Res Dev 1993; 30:210-223.

13 Matton L, Duvigneaud N, Wijndaele K, Philippaerts R, Duquet W, Beunen G, Claessens AL, Thomis M, Lefevre J: Secular trends in anthropometric characteristics, physical fitness, physical activity, and biological maturation in Flemish adolescents between 1969 and 2005. Am J Hum Biol 2007;19:345-357.

14 Foudriat BA, Di Fabio RP, Anderson JH: Sensory organization of balance responses in children 3-6 years of age: a normative study with diagnostic implications. Int J Pediatr Otorhinolaryngol 1993;27:255-271.
15 Forssberg H, Nashner LM: Ontogenetic development of postural control in man: adaptation to altered support and visual conditions during stance. J Neurosci 1982;2: 545-552.

16 Bawa P: Neural development in children: a neurophysiological study. Electroencephalogr Clin Neurophysiol 1981;52:249-256.

17 Era P, Sainio P, Koskinen S, Haavisto P, Vaara M, Aromaa A: Postural balance in a random sample of 7,979 subjects aged 30 years and over. Gerontology 2006;52:204213.

18 Hausdorff JM, Edelberg HK, Mitchell SL, Goldberger AL, Wei JY: Increased gait unsteadiness in community-dwelling elderly fallers. Arch Phys Med Rehabil 1997;78:278283.

19 Granacher U, Bridenbaugh S, Muehlbauer T, Wehrle A, Kressig RW: Age-related effects on postural control under multi-tasking conditions. Gerontology 2010, in press.

20 Blanchard Y, Carey S, Coffey J, Cohen A, Harris T, Michlik S, Pellecchia GL: The influence of concurrent cognitive tasks on postural sway in children. Pediatr Phys Ther 2005;17:189-193.

-21 Lundin-Olsson L, Nyberg L, Gustafson Y: 'Stops walking when talking' as a predictor of falls in elderly people. Lancet 1997;349: 617.

22 Beauchet O, Annweiler C, Dubost V, Allali G, Kressig RW, Bridenbaugh S, Berrut G, Assal F, Herrmann FR: Stops walking when talking: a predictor of falls in older adults? Eur J Neurol 2009;16:786-795.

23 Blimkie CJ: Age- and sex-associated variation in strength during childhood: anthropometric, morphologic, neurologic, biomechanical, endocrinologic, genetic, and physical activity correlates; in Gisolfi CV, Lamb DR (eds): Perspectives in Exercise Science and Sports Medicine: Youth, Exercise, and Sport. Indianapolis, Benchmark, 1989, vol 2, pp 99-163.

24 Martin JC, Farrar RP, Wagner BM, Spirduso WW: Maximal power across the lifespan. J Gerontol A Biol Sci Med Sci 2000;55:311-316.

25 Heeboll-Nielsen K: Muscle strength of boys and girls: 1981 compared to 1956. Scand J Sports Sci 1982;4:37-43.

26 Ferretti G, Narici MV, Binzoni T, Gariod L, Lebas JF, Reutenauer H, Cerretelli P: Determinants of peak muscle power - effects of age and physical conditioning. Eur J Appl Physiol 1994;68:111-115.

27 Larsson L, Grimby G, Karlsson J: Muscle strength and speed of movement in relation to age and muscle morphology. J Appl Physiol 1979;46:451-456.

28 McNeil CJ, Vandervoort AA, Rice CL: Peripheral impairments cause a progressive age-related loss of strength and velocity-dependent power in the dorsiflexors. J Appl Physiol 2007;102:1962-1968.
29 Bean JF, Kiely DK, Herman S, Leveille SG, Mizer K, Frontera WR, Fielding RA: The relationship between leg power and physical performance in mobility-limited older people. J Am Geriatr Soc 2002;50:461-467.

30 Pijnappels M, van der Burg PJ, Reeves ND, van Dieen JH: Identification of elderly fallers by muscle strength measures. Eur J Appl Physiol 2008; 102:585-592.

- 31 Belanger AY, McComas AJ: Contractile properties of human skeletal-muscle in childhood and adolescence. Eur J Appl Physiol 1989;58:563-567.

32 Granacher U, Gollhofer A, Strass D: Training induced adaptations in characteristics of postural reflexes in elderly men. Gait Posture 2006;24:459-466.

- 33 Granacher U, Muehlbauer T, Bridenbaugh S, Bleiker E, Wehrle A, Kressig RW: Balance training and multi-task performance in seniors. Int J Sports Med 2010;31:353-358.

- 34 Granacher U, Gruber M, Strass D, Gollhofer A: The impact of sensorimotor training in elderly men on maximal and explosive force production capacity (in German). Dtsch Z Sportmed 2007;58:446-451.

35 Granacher U, Muehlbauer T, Maestrini L, Zahner L, Gollhofer A: Can balance training promote balance and strength in prepubertal children? J Strength Cond Res 2010, in press.

36 Granacher U, Gruber M, Gollhofer A: Resistance training and neuromuscular performance in seniors. Int J Sports Med 2009;30: 652-657.

37 Granacher U, Gruber M, Gollhofer A: The impact of sensorimotor training on postural control in elderly men (in German). Dtsch Z Sportmed 2009;60:387-393.

38 Crawley-Coha T: Childhood injury: a status report, part 2. J Pediatr Nurs 2002;17:133136.

39 Fischer S: Sturzprävention gehört ins Repertoire. Mobile 2010;1:16-17.

40 Tinetti ME: Clinical practice. Preventing falls in elderly persons. N Engl J Med 2003; 348:42-49.

41 Chang JT, Morton SC, Rubenstein LZ, Mojica WA, Maglione M, Suttorp MJ, Roth EA, Shekelle PG: Interventions for the prevention of falls in older adults: systematic review and meta-analysis of randomised clinical trials. BMJ 2004;328:680-687.

42 Hadders-Algra M, Brogren E, Forssberg H: Training affects the development of postural adjustments in sitting infants. J Physiol 1996; 493:289-298

43 Ledebt A, Becher J, Kapper J, Rozendaalr RM, Bakker R, Leenders IC, Savelsbergh GJ: Balance training with visual feedback in children with hemiplegic cerebral palsy: effect on stance and gait. Motor Control 2005; 9:459-468 
-44 Collard DC, Chinapaw MJ, Verhagen EA, Bakker I, van Mechelen W: Effectiveness of a school-based physical activity-related injury prevention program on risk behavior and neuromotor fitness: a cluster randomized controlled trial. Int J Behav Nutr Phys Act 2010;7:9.

45 Collard DC, Verhagen EA, Chinapaw MJ, Knol DL, van Mechelen W: Effectiveness of a school-based physical activity injury prevention program: a cluster randomized controlled trial. Arch Pediatr Adolesc Med 2010; 164:145-150.

-46 Silsupadol P, Shumway-Cook A, Lugade V, van Donkelaar P, Chou LS, Mayr U, Woollacott $\mathrm{MH}$ : Effects of single-task versus dualtask training on balance performance in older adults: a double-blind, randomized controlled trial. Arch Phys Med Rehabil 2009;90:381-387.

47 Gillespie LD, Robertson MC, Gillespie WJ, Lamb SE, Gates S, Cumming RG, Rowe BH: Interventions for preventing falls in older people living in the community. Cochrane Database Syst Rev 2009;CD007146.

48 Madureira MM, Takayama L, Gallinaro AL, Caparbo VF, Costa RA, Pereira RM: Balance training program is highly effective in improving functional status and reducing the risk of falls in elderly women with osteoporosis: a randomized controlled trial. Osteoporos Int 2007; 18:419-425.

-49 Sihvonen S, Sipila S, Taskinen S, Era P: Fall incidence in frail older women after individualized visual feedback-based balance training. Gerontology 2004;50:411-416.

50 Steadman J, Donaldson N, Kalra L: A randomized controlled trial of an enhanced balance training program to improve mobility and reduce falls in elderly patients. J Am Geriatr Soc 2003;51:847-852.
51 Faigenbaum AD: Age- and sex-related differences and their implications for resistance exercise; in Baechle TR, Earle RW (eds): Essentials of Strength Training and Conditioning. Champaign, Human Kinetics, 2000, pp 169-186.

52 Falk B, Tenenbaum G: The effectiveness of resistance training in children. A meta-analysis. Sports Med 1996;22:176-186.

53 Faigenbaum AD, Zaichkowsky L, Westcott WL, Micheli LJ, Fehlandt AF: The effects of a twice per week strength training program on children. Pediatr Exerc Sci 1993;5:339346.

54 Faigenbaum AD, McFarland JE, Keiper FB, Tevlin W, Ratamess NA, Kang J, Hoffman JR: Effects of a short-term plyometric and resistance training program on fitness performance in boys age 12 to 15 years. J Sports Sci Med 2007;6:519-525.

55 Heidt RS Jr, Sweeterman LM, Carlonas RL, Traub JA, Tekulve FX: Avoidance of soccer injuries with preseason conditioning. Am J Sports Med 2000;28:659-662.

56 Latham NK, Bennett DA, Stretton CM, Anderson CS: Systematic review of progressive resistance strength training in older adults. J Gerontol A Biol Sci Med Sci 2004;59:48-61.

57 Fielding RA, LeBrasseur NK, Cuoco A, Bean J, Mizer K, Fiatarone Singh MA: High-velocity resistance training increases skeletal muscle peak power in older women. J Am Geriatr Soc 2002;50:655-662.

58 Rubenstein LZ, Josephson KR, Trueblood PR, Loy S, Harker JO, Pietruszka FM, Robbins AS: Effects of a group exercise program on strength, mobility, and falls among fallprone elderly men. J Gerontol A Biol Sci Med Sci 2000;55:317-321.

59 King AC: Interventions to promote physical activity by older adults. J Gerontol A Biol Sci Med Sci 2001;56:36-46.
60 Ransdell LB, Taylor A, Oakland D, Schmidt J, Moyer-Mileur L, Shultz B: Daughters and mothers exercising together: effects of homeand community-based programs. Med Sci Sports Exerc 2003;35:286-296.

61 Ransdell LB, Robertson L, Ornes L, MoyerMileur L: Generations exercising together to improve fitness (GET FIT): a pilot study designed to increase physical activity and improve health-related fitness in three generations of women. Women Health 2004;40: 77-94.

62 Wolf SL, Barnhart HX, Ellison GL, Coogler CE: The effect of Tai Chi Quan and computerized balance training on postural stability in older subjects. Atlanta FICSIT Group. Frailty and Injuries: Cooperative Studies on Intervention Techniques. Phys Ther 1997;77: 371-381.

63 Cherng RJ, Liu CF, Lau TW, Hong RB: Effect of treadmill training with body weight support on gait and gross motor function in children with spastic cerebral palsy. Am J Phys Med Rehabil 2007;86:548-555.

64 Häkkinen K, Kallinen M, Izquierdo M, Jokelainen K, Lassila H, Malkia E, Kraemer WJ, Newton RU, Alen M: Changes in agonist-antagonist EMG, muscle CSA, and force during strength training in middle-aged and older people. J Appl Physiol 1998;84:1341-1349.

65 Campbell AJ, Robertson MC, Gardner MM, Norton RN, Buchner DM: Falls prevention over 2 years: a randomized controlled trial in women 80 years and older. Age Ageing 1999; 28:513-518.

66 Baechle TR, Earle RW, Wathen D: Resistance training; in Baechle TR, Earle RW (eds): Essentials of strength training and conditioning. Champaign, Human Kinetics, 2000, pp 395-425. 